\title{
O crowdsourcing como fator de competitividade na publicidade: 0 caso da Teaser Propaganda
}

\author{
Anderson Diego Farias da Silva* \\ Mayara Barbosa da Cunha*** \\ Fernanda Martins Ramos****
}

\begin{abstract}
Resumo
A dinâmica das transformações geradas pela globalização e o desenvolvimento das tecnologias da informação e comunicação afetam diretamente as relações econômicas e sociais no mundo contemporâneo. Nesse contexto, as organizações precisam desenvolver novas estratégias de aperfeiçoamento de seus produtos e serviços. $\mathrm{O}$ objetivo deste estudo reside em compreender o histórico do crowdsourcing na publicidade, ressaltando a importância da participação coletiva no advento das novas tecnologias. Desenvolveu-se um estudo de caso qualitativo a fim de compreender os principais conceitos relacionados ao crowdsourcing em estratégias publicitárias. Os resultados demonstraram como essa estratégia pode ser útil para formar uma rede de colaboradores, aproximando usuário e marca, convertendo-o de comprador em cliente.
\end{abstract}

Palavras-chave: Crowdsourcing. Estratégia. Teaser Propaganda.

* Professor da Universidade Federal de Pernambuco. Mestre e doutorando em Administração pelo Programa de Pós-Graduação em Administração da Universidade Federal de Pernambuco. Especialista em Administração de Marketing pela Universidade de Pernambuco. E-mail: andersondiego6@ gmail.com

** Discente do curso de Bacharelado em Administração pela Universidade Federal de Pernambuco. E-mail: mayarabcunha@hotmail.com

*** Discente do curso de Bacharelado em Administração pela Universidade Federal de Pernambuco. E-mail: fernandamartinsramos@gmail.com

http://dx.doi.org/10.5335/rtee.v22i47.6836

Submissão: 26/06/2016. Aceite: 15/08/2016. 


\section{Introdução}

Com o advento de um conceito de mercado mais integrado e o registro de maior acesso dos consumidores às plataformas tecnológicas, a sociedade contemporânea vive a consolidação das redes de conhecimento e de inovação, redes que se articulam como novos mecanismos da globalização. Essa sociedade, já prenunciada por Manuel Castells em sua obra Sociedade em rede (2010), revela a transformação estrutural assentada sob o poder da comunicação e tecnologia, chamando a atenção para o indivíduo, que ressurge perante a sociedade como ser ativo e soberano a esse poder. Segundo Castells (2010), a sociedade determina o sucesso ou fracasso de uma tecnologia e a molda de acordo com seus costumes, necessidades e preferências. Pode-se afirmar que a aceitação da inovação, sobretudo tecnológica, é fundamental para legitimar e fortalecer essa produção de conhecimento na sociedade pós-industrial, ${ }^{1}$ de maneira que os produtos e serviços prestados sejam antes validados pelo crivo social, levando-se em conta aspectos relevante para a comunidade (JULIEN, 2010).

Em busca do feedback e de ações inovadoras para o aperfeiçoamento de seus bens, as empresas passaram a trabalhar com novas técnicas de obtenção desses recursos, os chamados brainstorm, método que propõe a reunião de ideias e projetos de maneira a estimular o conhecimento e a inovação (TADEL, 2011), e o crowdsourcing, conceito ligado à colaboração coletiva para desenvolver inovação e aprimorar produtos (HOWE, 2009). A aplicação de tais conceitos nos levou a um novo modelo de desenvolvimento da inovação, que ampliou sua área de atuação e se livrou das limitações de salas de reuniões ao abrir as portas para ideias e pessoas de diferentes partes do mundo e classes sociais que se uniram em prol de um mesmo objetivo.

Para vivenciarmos essa interação de maneira tão intensa, um longo caminho teve de ser percorrido até a fundamentação da internet e das mídias sociais, nos moldes que conhecemos hoje. Mesmo que inconscientemente a sociedade pós-industrial dedica-se a trabalhar ativamente em todos os processos de criação, vislumbrando um novo produto ou serviço, o senso crítico e a sensibilidade para encontrar maneiras de associar a praticidade à inovação tornaram-se um trunfo para os gestores empresariais que entenderam que a proximidade com o usuário acelera de modo significativo a eficiência dos resultados.

A visão do conhecimento como um bem intangível cada vez mais valorizado, desvelado a partir da Segunda Guerra Mundial, revelou a necessidade de buscar novas fontes de produção. Nesse sentido, o crowdsourcing surge como um método importante para o desenvolvimento de informação e conhecimento: bens

Teoria e Evidência Econômica - Ano 22, n. 47, p. 413-432, jul./dez. 2016 
caracterizados como matéria-prima da inovação criativa-tecnológica tão ansiada pelas organizações para permanecer em condição competitiva no mercado global (NASCIMENTO et al., 2014; HOWE, 2009).

Visando explorar a agregação de valor desses mecanismos - conhecimento e inovação - em uma empresa e vislumbrar como isso ocorre, o presente estudo terá o objetivo de compreender a aplicabilidade e os resultados do crowdsourcing na área de marketing e publicidade, por meio da análise do caso da Teaser Propaganda. Estruturado em cinco seções, a primeira apresenta a relação entre a publicidade e a participação coletiva, ressaltando a importância das novas tecnologias e do novo contexto de rede atual, analisando o fator competitivo dessa democracia para as empresas. A seguir, será apresentada a plataforma de crowdsourcing 99 Designs, que reúne concursos de design gráfico voltados para a publicidade, promovendo um ambiente competitivo amigável e seguro. Posteriormente, é apresentado o histórico do crowdsourcing na publicidade, com a apresentação de casos de sucesso e de insucesso. Por fim, será apresentado o caso da Teaser Propaganda, em que se descreve a estratégia que a organização utilizou na implantação do crowdsourcing nas redes sociais para a criação de seu próprio portal eletrônico.

\section{Fundamentação teórica}

As seções a seguir foram elaboradas com o intuito de fundamentar a importância da relação empresa-consumidor dentro do escopo da publicidade bem como esclarecer questões sobre como o uso do crowdsourcing pode romper com a estrutura tradicional de se fazer marketing e agregar vantagem competitiva com relação ao mercado.

\subsection{A publicidade e a participação coletiva}

Com o crescimento da integração dos mercados, em muitas situações, o fator determinante para a sobrevivência dos negócios poderá depender da intensidade em que cada um investe em seus ativos intangíveis. Friedrich List foi pioneiro ao introduzir o conceito de investimento intangível, no século XIX, afirmando que a situação de um país resulta da acumulação de todas as descobertas, invenções, melhorias, aperfeiçoamentos e esforços de todas as gerações antecedentes e que isso forma o capital intelectual da raça humana (FREEMAN; SOETE, 1997). Considerando o marketing como bem intangível, Kotler e Armstrong (1996), apresentam-no 
como um fator de vantagem competitiva para a organização. Essa vantagem competitiva poderá ser obtida por meio da influência na reputação de uma instituição, representação simbólica que poderá valorizá-la ou prejudicá-la diante dos usuários e os fornecedores.

Segundo Cocco, Galvão e Silva (2003), estamos diante de alterações sistêmicas não compreendidas pelo capitalismo industrial e que, portanto, sugerem o uso do termo capitalismo cognitivo, como forma mais adequada de representar essas transformações, ou seja, compreender um ambiente dinâmico em que o sistema econômico vigente privilegia o trabalho imaterial, que cria valor competitivo nas empresas, pois o conhecimento é concebido como um tipo de mercadoria. Podemos considerar patrimônios intangíveis bens como know-how, direitos autorais, patentes, recursos humanos ou tecnologias. Esses bens estão fortemente vinculados ao desenvolvimento de inovação, tanto tecnológica quanto na gestão administrativa do patrimônio, o que reforça a importância da atividade inovativa dentro da organização, de forma a mantê-la presente e participativa no mercado.

$\mathrm{O}$ aumento da conectividade que as novas tecnologias da informação e comunicação provocaram, que somada à ascensão de um novo perfil de indivíduo que busca novos contatos a fim de difundir ideias com vistas à geração de algo inovador, é considerado um dos maiores impulsionadores da inovação (CASTRO, 2011; HOWE, 2009). Conforme argumenta Wersig, "o universo do conhecimento está se desmembrando de forma crescente por muitas razões. Uma delas, certamente, é o absoluto volume, que torna impossível para qualquer pessoa acumular todo o conhecimento disponível” (1993, p. 232).

O surgimento de novas formas de comunicação, tais como as plataformas tecnológicas colaborativas e o encontro de novas pessoas que colaboram e difundem as ideias é o que Hall (1994) intitula de mudança tecnológica incremental e gradual, que é amplamente aceita, principalmente, em virtude da teoria evolucionária (JOHNSON, 2001). Desse modo, no contexto da sociedade em rede, observa-se que cada vez mais as empresas se aproximam uma das outras e de seus clientes, gerando uma espécie de movimento dinâmico de cocriação no processo de desenvolvimento de novos produtos e serviços (CASTELLS, 2010).

$\mathrm{Na}$ área publicitária não é diferente, pois, as empresas estão cada vez mais fortalecendo esses novos canais de comunicação com seus consumidores. O público participa de campanhas publicitárias por meio do envio de fotos e vídeos para concursos de marcas, os usuários da rede, por se sentirem inseridos no processo de criação, criam peças publicitárias para se manifestarem positiva ou negativamente em relação a produtos ou serviços, são criadas agências on-line, visando 
à colaboração criativa de terceiros conectados virtualmente, etc. Dessa forma, a empresa tem essa nova estratégia colaborativa, que gera lucros não apenas informacionais, mas econômicos também (AMARAL FILHO, 2014).

A inserção do crowdsourcing na publicidade está alterando a forma de relação entre agentes publicitários, marcas e clientes. Porém, essa expansão encontra alguns empecilhos, pois:

A maioria de nós seja como eleitores, investidores consumidores ou administradores acredita que o conhecimento valioso está concentrado em muito poucas mãos (ou, melhor, em muito poucas cabeças). Nós presumimos que a chave para solucionar problemas ou tomar boas decisões é encontrar aquela pessoa certa que terá a resposta. [...] sentimos a necessidade de "caçar o especialista" [...] caçar o especialista é um equívoco, e um equívoco caro. Nós devemos parar de caçar e, em vez disso, perguntar a massa (que, claro, inclui tanto os gênios quanto todos os outros) (SUROWIECKI, 2006, p. 13).

O crowdsourcing na publicidade possibilita a utilização da inteligência coletiva, direcionando-a para seus próprios fins (JENKINS, 2009). Nesse novo cenário de conectividade, os conteúdos e informações não fluem mais de forma unilateral e o consumidor deixa de ser um agente passivo. Assim, esse indivíduo passa a ter um poder maior de interação e comunicação, ou seja, é agora uma espécie de porta-voz da marca, participando constantemente de discussões em comunidades, defendendo a marca ou gerando novas demandas. Dessa maneira, esse consumidor torna-se um agente constituído por um discurso que poderá influenciar as organizações.

Essa participação do público consumidor poderá ser compreendida a partir do equilíbrio entre os conceitos do fascínio e da frustração. Com relação ao fascínio, ele ocorre na medida em que o indivíduo tem acesso às tecnologias da informação e comunicação e passa a ser ouvido e visto por empresas, podendo expor opiniões e habilidades. Em se tratando da frustração, ela ocorre com a empresa, marcas, pessoas e governos. A junção desses dois sentimentos faz com que os consumidores criem canais para mostrar sua insatisfação em relação a um produto, publicando vídeos, compartilhando informações acerca da marca e participando ativamente de campanhas (AMARAL FILHO, 2014).

O gosto por emitir opiniões é uma característica intrínseca do ser humano, que sempre deseja se expressar com relação a determinados assuntos de seu interesse, aconselhando ou desaconselhando. Nesse sentido, a propaganda boca a boca ocorre quando esses comentários referem-se à marca, e essa é uma prática constante desde o aparecimento das opções de escolha (AMARAL FILHO, 2014). A opinião que o consumidor produz e transmite a outros tem a credibilidade desses ouvintes, pois quem opina, provavelmente, experimentou o produto/serviço. 
No ambiente mercadológico, a propaganda boca a boca está adquirindo ao longo dos anos grande relevância no desenvolvimento das estratégias de marketing e comunicação das empresas, passando a ser utilizada em função da experiência dos consumidores com os produtos, visando atrair a atenção das pessoas para eles. Desse modo, as empresas estrategicamente cedem espaços em seus portais eletrônicos, no intuito de obter informações do público sobre a marca, buscando apreender informações sobre indicações e benefícios que podem ser acrescidos ao produto.

O marketing viral (BARICHELL, 2011) faz uso da internet como meio de propagação da mensagem. Para Felinto, "o termo define uma estratégia de comunicação fundada na ideia de explorar redes sociais pré-existentes para produzir aumentos exponenciais de propagação de uma marca ou conceito, de forma similar ao que sucede numa epidemia" (2007, p. 35). Isso significa que a viralização não é um fato atual, já que se registra que, mesmo antes da existência da web 2.0, que é uma plataforma colaborativa por natureza, interativa e dinâmica, os usuários criavam o conteúdo nesses sites tanto quanto eles o consumiam (O'REILLY, 2005), pois era possível viralizar mensagens, por meio de e-mails, salas de bate-papo e programas de mensagens instantâneas, como o ICQ. O que ocorre nos dias atuais é a ascensão da propagação de todo tipo de mensagem pelo que distingue a web 2.0 da 1.0, ou seja, a possibilidade de compartilhamento. Dessa forma, os usuários podem publicar e compartilhar vídeos em seus blogues e redes sociais, além de utilizar todas as ferramentas disponíveis para disponibilizar endereços de vídeos, por exemplo, que viralizam.

Os estudos desenvolvidos por Vickery e Wunsch-Vincent (2007) classificam o conteúdo criado pelo usuário como sendo um conteúdo disponibilizado na internet, reflexo de certo esforço criativo e com produção fora de práticas e rotinas profissionais. Para os autores, a maioria desse conteúdo é feita sem a expectativa de haver lucro ou remuneração e as motivações seriam a conexão com os pares, autoexpressão e aquisição de notoriedade.

Porém, diante do contexto da inovação aberta (open innovation), compreendida por Chesbrough (2003) como o ato das empresas explorarem recursos de outras organizações externas visando à redução de custos relacionados ao desenvolvimento tecnológico, os riscos de entrada no mercado e o tempo de desenvolvimento de um novo produto, além da sustentação de que o processo de inovação deva ser mais colaborativo, buscando acessar conhecimento a partir de diversos atores externos, dessa maneira, as empresas passam a ter uma visão estratégica de não estarem apenas voltadas para as criações internas, mas também, para as tendências do ambiente externo. Por esse motivo, algumas empresas têm um olhar diferenciado 
para esses virais da internet, por compreenderem o grande alcance que esses vídeos detêm. Exemplificando, aproveita-se esse sucesso para engrenar a marca por meio de campanhas publicitárias que promovam fácil identificação com o público consumidor (AMARAL FILHO, 2014).

A democratização da internet abre espaço para novas oportunidades de expressão, já que de um lado temos as empresas de mídia acelerando o fluxo de conteúdo por meio dos canais de distribuição, visando aumentar o lucro e o mercado, de outro lado, os consumidores, cada vez mais inseridos na rede, aprendendo a utilizar diferentes tecnologias para interagir com outros consumidores e com a empresa, sentindo-se satisfeito por participar de uma marca com a qual se identificam (JENKINS, 2009). Em decorrência desses aspectos, o consumidor sente-se ativo e acolhido pela marca, que o convida a se inserir em sua comunidade. Essa é também uma forte estratégia das empresas, que estabelecem um vínculo afetivo com seus clientes, de forma que se gera um comprometimento e um processo de fidelização que aproxima o consumidor e fortalece a marca, fazendo com que o consumidor escolha seu produto/serviço, independente de ser mais ou menos vantajoso.

\subsection{Crowdsourcing e o 99 Designs}

Em sua obra $O$ poder das multidões, Jeff Howe (2009) definiu o termo crowdsourcing como sendo um modelo de produção que utiliza a inteligência coletiva e a capacidade de indivíduos disseminados pela rede para resolver problemas, criar soluções ou desenvolver novas tecnologias. Por meio dessa perspectiva teórica, podemos suscitar o dito popular que afirma que duas cabeças pensam melhor do que uma, ou seja, o fato de que o crowdsourcing, por contar com mão de obra barata - já que seus executores são pessoas que fazem disso um lazer -, cria um forte instrumento para o desenvolvimento da inovação aberta (NASCIMENTO et al., 2014).

Corroborando com os argumentos suscitados por Howe (2009), o estudo desenvolvido por Zatti, Ferrari e Belalian (2012) destaca ainda que o crowdsourcing, em sua essência, dependeria da existência de uma multidão, seja para produzir um vídeo ou para editar um tópico na Wikipédia, por exemplo. Dessa maneira, pressupõe-se que inseridos em uma perspectiva da sociedade em rede, a inovação dependerá menos dos gênios individuais para ser uma propriedade produzida de forma colaborativa, em todo o seu processo de desenvolvimento (NASCIMENTO et al., 2014; GARCIA, 2012; CASTELLS, 2003).

Desse modo, o crowdsourcing carrega um valor intrínseco compreendido como a economia da reputação, uma vez que a reputação empresarial é considerada um 
capital intangível, cada vez mais visado no mercado, e que se não for bem gerenciado acarreta custos de difícil reparo para a empresa, assim, o crowdsourcing mostra que o ser humano nem sempre segue padrões egoístas ou oportunistas, pois, temos como exemplo a plataforma tecnológica colaborativa Wikipédia, na qual milhares de pessoas ao redor do mundo contribuem com conhecimento voluntariamente.

Conforme Howe (2009) existem quatro categorias de crowdsourcing:

a) Inteligência coletiva: princípio de que grupos contêm mais conhecimento do que pessoas isoladas;

b) Criatividade da multidão: princípio de que a multidão tem grande energia criativa;

c) Poder de voto da multidão: aproveita opinião das pessoas para organizar grandes volumes de informação (classificar);

d) Crowdfunding: aproveita renda coletiva, permitindo que grupos sejam fontes de recursos financeiros.

Com relação à delimitação de regras, o intuito é a promoção da eficiência na iniciativa de crowdsourcing, pois, Howe (2009) argumenta que a empresa deverá saber escolher a multidão certa para o desenvolvimento do modelo, ou seja, nunca perguntar o que a multidão pode fazer por você e, sim, o contrário, escolher os incentivos certos e usar os filtros corretamente.

A plataforma de crowdsourcing mais importante no ramo do design gráfico voltado para o marketing é o 99 Designs, que tem a função de trazer a inovação para o ramo, com objetivo de promover um ambiente interativo, profissional e seguro, no qual os usuários poderão competir, compartilhar informações e conquistar novos clientes (SILVA, 2001). Assim, essa plataforma poderá promover concursos voltados para o design de identidade (logotipo, papelaria), web design (background para a rede social Twitter, banners de propagandas) e alguns outros produtos, entretanto, para fins deste estudo, delimitaremos a compreensão acerca da criação de logotipos.

Inicialmente, o usuário deverá criar um perfil e poderá promover e participar de concursos, compartilhando informações. Ao criar um novo concurso, o usuário define o que quer (logotipo, banner), em seguida, apresentará uma breve descrição do negócio e do ramo de atuação de sua empresa, podendo escolher o estilo do logo desejado por ele. Adiante, define características desejáveis para o logo, por meio de um gráfico, podendo especificar a cor desejada. A plataforma tecnológica faz uma relação entre cores e sentimentos (exemplo: vermelho reflete paixão, raiva, vigor, amor, perigo). Além disso, é possível selecionar a plataforma em que o logo será 
utilizado: impresso, on-line, tela. Por fim, o usuário pode anexar quaisquer imagens para auxiliar o designer na criação.

\section{Procedimentos metodológicos}

O presente estudo está fundamentado em pesquisas bibliográficas (LIMA e MIOTO, 2007) realizadas em periódicos, livros e documentos oficiais, sob a lente teórica dos conceitos inerentes ao crowdsourcing, compreendido como uma estratégia competitiva as empresas, no que se refere à estratégia publicitária.

Com relação à natureza do estudo, trata-se de uma abordagem qualitativa, que visa analisar o ambiente natural como fonte de dados e o pesquisador como instrumento (MARTINS; THEÓPHILO, 2007). O argumento proposto por Richardson corrobora essa definição, ao afirmar que "os estudos que empregam uma metodologia qualitativa podem descrever a complexidade de determinado problema, analisar a interação de certas variáveis, compreender e classificar processos dinâmicos e vividos por grupos sociais" (1999, p. 39).

Em se tratando do enfoque, esta pesquisa possui um caráter exploratório, pois, o objetivo é analisar os fatores estratégicos que o crowdsourcing possibilita para as agências publicitárias no contexto atual. Além disso, foram analisados casos concretos e contextualizados no intuito de facilitar esse entendimento.

Quanto à estratégia de pesquisa, utilizou-se o estudo de caso, compreendido por Creswell (2010) como uma estratégia de investigação que diz respeito a um programa, um evento, uma atividade, um processo ou um ou mais indivíduos. No processo de escolha dessa estratégia de investigação, observamos o quão era necessária sua aplicação pelas condições contextuais serem extremamente pertinentes para se compreender o fenômeno estudado: o caso da Teaser Propaganda, no intuito de verificar a aplicabilidade e os resultados do crowdsourcing na área de marketing e publicidade.

No processo de construção do plano de coleta de dados, optou-se pela realização de uma pesquisa documental por meio do acesso a relatórios, papers e demais publicações a fim de encontrar dados que corroborassem a melhor observação do caso estudado.

$\mathrm{Na}$ etapa de interpretação dos dados, foram realizados procedimentos de triangulação e validação, buscando excluir possíveis interpretações equivocadas (GASKELL; BAUER, 2002; STAKE, 1999). As tipologias nos procedimentos de triangulação, conforme argumenta Denzin (2009), são a triangulação de fontes de dados, baseada na utilização de diversas fontes de informação e a triangulação de 
investigadores, que sugere que mais de um pesquisador possa analisar os mesmos dados. Esta pesquisa contou com o apoio de estudiosos e pesquisadores que compõem o Lócus de Investigação em Economia Criativa da Universidade Federal de Pernambuco para a triangulação de métodos, que se refere à utilização de dois ou mais métodos de pesquisa, e para a triangulação da teoria, que submete os achados ao escrutínio teórico.

\section{Crowdsourcing na publicidade: o caso da Teaser Propaganda}

A publicidade participativa não é algo recente, nem apenas fruto da ascensão da internet, ocorria antes mesmo da consolidação desses acontecimentos. Na década de 1990, observa-se uma iniciativa de crowdsourcing com consumidores da empresa de vestuário Gang Gaúcha, que ao utilizar o slogan A loja que te entende buscou investir na comunicação com o público consumidor, visando atraí-los para que eles pudessem colaborar na criação de suas campanhas publicitárias. As pessoas foram convidadas a enviar sugestões de campanha para as coleções de verão ou inverno, e essa foi a maneira pela qual o público jovem conseguiu lugar para se expressar. Além disso, o slogan pretendia confirmar esse compromisso com seu público, que estava em sincronia com a proposta de valor da marca (GANG GAÚCHA, 2015; AMARAL FILHO, 2014).

Seguindo um percurso semelhante, a agência Teaser Propaganda surgiu no período chamado de terceira geração de agências de publicidade e propaganda no estado de Sergipe. A primeira geração era formada basicamente por profissionais de outros estados, visto que não havia curso de Publicidade e Propaganda nas universidades sergipanas. Já a segunda geração contava com profissionais locais e ações que visavam os meios de comunicações convencionais. Por fim, a terceira geração chega buscando mudar o foco dos meios de comunicações convencionais para os alternativos, as mídias digitais, mas sem extinguir as mídias convencionais de fato.

Com um site criado a partir de um brainstorm que envolveu centenas de cocriadores externos (Figura 1), a Teaser Propaganda buscava se diferenciar das demais agências do setor e apostou no crowdsourcing para se destacar em um cenário incerto e ainda pouco desenvolvido no Brasil (TEASER PROPAGANDA, 2012). 
Figura 1 - Case site cocriativo Um projeto. Vários autores

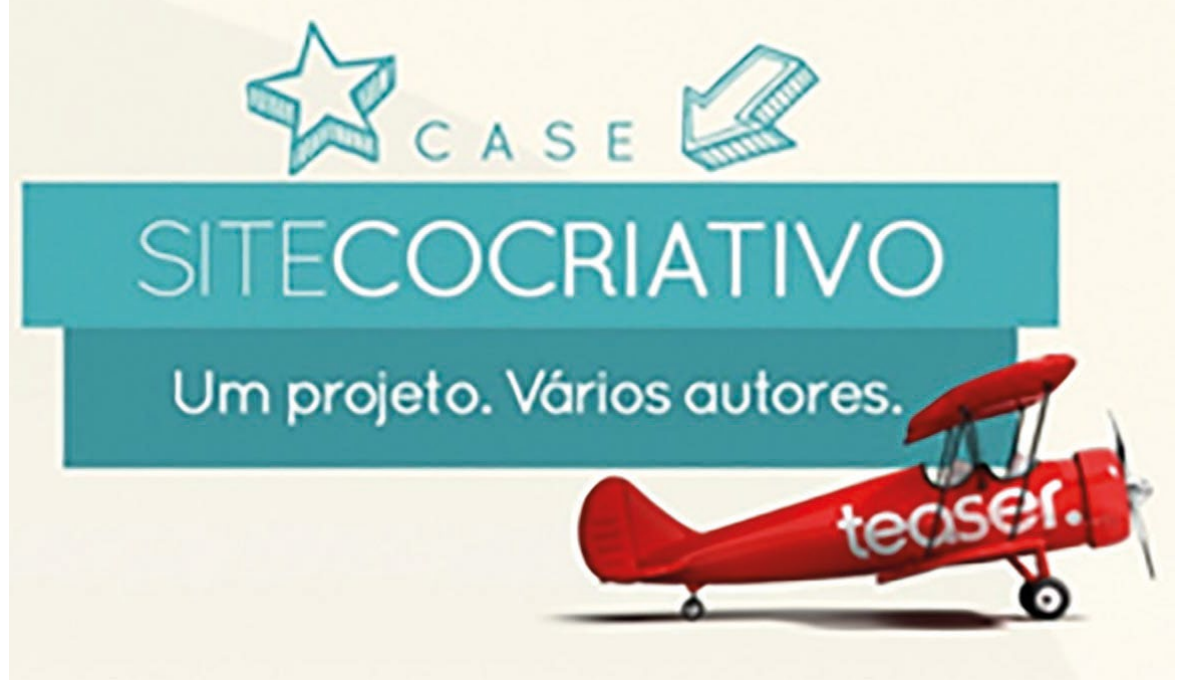

Fonte: Teaser Propaganda (2012).

A estratégia da agência era desenvolver seu novo site e por meio dele aumentar o diálogo com a comunidade on-line e criar um posicionamento na web para a marca, foi em busca de uma forma original e eficiente para atingir seus objetivos. Baseada na ideia de que todos os profissionais lidam com prazo e de que para acelerar o processo de criação precisam de mais pessoas, o que resulta em mais prazo, a Teaser desenvolveu uma ação que se iniciava ainda no brainstorm e se aliava ao crowdsourcing.

O site foi lançado e o sucesso dessa plataforma de contribuições foi tão grande que em menos de 48 horas a Teaser tornou-se a empresa do segmento local com o maior número de fãs, foi citada em sites de referência, como o Inovadores ESPM e no site especializado em crowdsourcing, o IdeasMe, além de se tornar referência em estratégia para redes sociais. As ideias desse projeto não só ajudaram a desenvolver o novo site da Teaser, como também incentivaram a criação de novos projetos.

\section{Apresentação e discussão dos resultados}

Nesta seção apresentam-se as discussões referentes à aplicação da ferramenta crowdsourcing em uma agência de publicidade, especificamente, a empresa Teaser Propaganda. Para tanto, buscou-se analisar conceitos interligados sobre o que é 
apregoado acerca desse assunto na literatura organizacional com a sua prática. Desse modo, observamos que a escolha pelo presente caso corroborou para a compreensão sobre como o crowdsourcing e a inovação aberta valorizam as contribuições externas e buscam não se limitar ao espaço físico da organização, tampouco aos meios de comunicação convencionais.

Inicialmente, ao analisarmos o caso da Teaser Propaganda, percebemos que a organização almejava obter um diferencial competitivo em seu mercado de atuação. Nesse sentido, desenvolveu uma nova estratégia de comunicação direcionada ao seu público consumidor, tornando-o uma espécie de cocriador de seus produtos e serviços, por meio das redes sociais. Dessa forma, a Teaser não só conseguiu desenvolver seu site de forma inovadora, como conseguiu mostrar que não devemos sempre esperar que os indivíduos ajam de forma egoísta ou interesseira baseados apenas em boas recompensas. Segundo Machado Filho (2006), esse comportamento oportunista pode ser justificado por questões intrínsecas aos seres e interações humanas, sendo, portanto, papel da instituição garantir medidas eficientes que minimizem tais ações.

Sendo assim, a empresa pode ser caracterizada como uma startup, modelo de negócio empreendedor, em que o investimento em tecnologia e ideias inovadoras traduz sua principal fonte de lucro (MUNHOZ et al., 2013). Por meio da inovação estratégica, a empresa aperfeiçoou-se em termos de competitividade, tendo a internet como viabilizadora da proposta.

As ações desenvolvidas pela agência tiveram o intuito de aproximar pessoas e ideias, visando agregar valor ao produto final, além de promover a boa reputação da nova marca. Assim, observamos que a reputação atua como um fator determinante e que influência no engajamento e na produtividade dos envolvidos no brainstorm, assim como na percepção de credibilidade por parte dos consumidores, além de estimular os funcionários, influenciando na produtividade.

No período em que foi desenvolvido o portal eletrônico da agência Teaser Propaganda, em 2011, não era comum no Brasil o uso assíduo de mídias digitais para esses fins, especialmente no estado de Sergipe. Dessa maneira, ao implantar esse modelo colaborativo, a empresa trouxe à tona um conceito que dialoga com o da inovação aberta, pois, conforme define Chesbrough (2003), neste modelo a empresa observa tendências externas e traz isso para dentro de si, e não necessariamente um funcionário ou colaborador está literalmente trabalhando na empresa, mas podem ser pessoas comuns, que se identificam com a marca e se sentem motivadas a contribuir. 
No caso específico da empresa estudada, observamos que a estratégia de uso da rede social Facebook e as iniciativas da promoção de uma hashtag intitulada \#CoCriadorDODIA dialogam com o que anteriormente denominamos de propaganda boca a boca (AMARAL FILHO, 2014). Nesse sentido, percebe-se que após essas iniciativas, os seguidores da página eram incentivados a postar frases criativas em troca da divulgação de sua foto pela empresa em sua fanpage, caracterizando um vínculo e uma espécie de reconhecimento. A partir disso, a agência Teaser Propaganda desenvolveu uma forte empatia com esses consumidores, convidando-os a se engajar na criação do seu portal eletrônico, além de encher a "sala de reunião" do brainstorm com pessoas de perfil criativo e colaborativo, caracterizando assim, a existência da multidão, conforme argumentaram Zatti, Ferrari e Belalian (2012).

Dessa forma, constituiu-se uma rede colaborativa de indivíduos que interagiam em torno da construção da marca, diferentemente, por exemplo, do que ocorreria nos moldes tradicionais de atuação da empresa fordista. Entretanto, como forma de atender aos requisitos básicos da estratégia de crowdsourcing, antes da criação do portal eletrônico, a agência Teaser Propaganda selecionou diversos colaboradores cujas ideias seriam inseridas no projeto, ou seja, a empresa utilizou filtros adequados para a escolha de colaboradores que mais se adaptassem à sua proposta de valor e criou incentivos que consolidassem essa proposição, que, nesse caso, foi a ação de distribuir bebida energética para os consumidores, perguntando-lhes como ela poderia deixá-los mais criativos, além de convidá-los para que criassem frases expressando as suas expectativas (GARCIA, 2012; HOWE, 2009; CASTELLS, 2003).

O uso do crowdsourcing como estratégia de negócio possibilita a utilização de uma mão de obra barata, visão partilhada pelos estudos de Howe (2009), pois, conforme observado no caso estudado, essa questão teve um forte impacto na redução de custos na criação do portal eletrônico da empresa Teaser, ou seja, os indivíduos que estiveram envolvidos nessa construção foram voluntários simpáticos à causa e não foram pagos de alguma forma para isso. Além disso, é possível enquadramos esse caso na categoria de criatividade de multidão, pois, foi utilizada a energia criativa de vários indivíduos reunidos, inclusive, fazendo referência ao princípio de inteligência coletiva, que prega que um grupo detém mais conhecimento do que um indivíduo isolado (NASCIMENTO; HEBER; LUFT, 2014).

Com relação às principais consequências alcançadas por essa empresa a partir do uso da estratégia do crowdsourcing, destacam-se o reconhecimento obtido no mercado publicitário, as premiações concedidas pelo segmento, além da inspiração para a realização de outros projetos com as ideias concebidas pelos intitulados "cocriativos". Esses acontecimentos geraram desdobramentos que estão sendo 
consolidados em iniciativas posteriores, tais como a estratégia A nova da Teaser, uma série de palestras virtuais inspiradas por sugestões desses seguidores, que contribui para a evolução desse mercado.

Analisando a distribuição de sua estrutura física, observamos que a empresa criou um recurso no corredor de acesso aos departamentos, onde os fãs da marca podem passar e interagir com os colaboradores da Teaser. O objetivo dessa medida é de estimular a equipe, fazendo-as trabalhar ao longo do dia cientes de que muitas pessoas estão atentas e apoiando o trabalho que está sendo desenvolvido. Esse fator reflete-se positivamente na produtividade da empresa, além de ser considerado um valor competitivo.

Em se tratando do capital reputacional da empresa Teaser Propaganda, analisamos que a sua ocorrência não apenas se estabeleceu no ambiente externo, mas, sobretudo, em seu ambiente interno pode ser registrado, uma vez que os próprios colaboradores estavam se encarregando de desenvolver a chamada propaganda boca a boca, incentivados pelo argumento de que faziam parte da equipe (AMARAL FILHO, 2014; MACHADO FILHO, 2006).

Aliando o pensamento estratégico ao da inovação, percebemos que a empresa buscou agregar valor competitivo à sua marca por meio da introdução de conceitos do crowdsourcing no mercado publicitário brasileiro. Além disso, o intuito era não deixar que a iniciativa pudesse ser interpretada como algo isolado, pois a questão central era demonstrar que a criação de ambientes de colaboração permitiria que novas iniciativas pudessem ser geradas, buscando extrair o máximo do sucesso de cada caso, visando ao fortalecimento da própria marca, como fizeram na criação de um vídeo divulgado em uma rede social (YouTube) que explica o processo de cocriação do site, demonstrando as consequências e como as estratégias que foram implantadas visam ao alcance de objetivos estratégicos da organização, atraindo assim, não só os seguidores conquistados durante o processo de formulação, mas também pessoas que poderiam vir a conhecer esse caso (PINTO; ANHOLON, 2006).

Por fim, o estudo do presente caso fez referência aos custos transacionais de controle de pessoal, ou seja, no que tange ao fato de ter colaboradores estimulados e alinhados à estratégia da empresa, essa situação poderia diminuir as consequências dos riscos de oportunismo interno. A redução desse risco, consequentemente, acarretaria na diminuição de custos transacionais de controle desse pessoal, desenvolvendo, assim, uma equipe confiável e integralizada (MACHADO FILHO, 2006). 


\section{Considerações finais}

O estudo do presente case à luz de conceitos extraídos da literatura organizacional acerca do crowdsourcing, no contexto do capitalismo cognitivo, permite compreender em quais condições o conhecimento funciona como uma espécie de mercadoria - um bem simbólico - e de como o acesso à informação poderá ser livre para a grande maioria das pessoas, ficando cada vez mais comum a existência de uma forte interação entre o consumidor e a respectiva organização detentora da marca. Nessa perspectiva, os consumidores têm mais poder de ação com base nas informações que podem ser geradas sobre as organizações por meio das tecnologias de informação e comunicação, podendo, inclusive, demonstrar apreensões positivas ou negativas acerca da atuação desses negócios.

Entendendo que o marketing é caracterizado como um capital intangível e que poderá, portanto, interferir diretamente na receita da empresa, torna-se fundamental conhecer novas estratégias que possam ser incrementadas a esse capital, no intuito de dinamizar a receita do negócio e elevar o seu valor competitivo. Nesse sentido, analisar o desenvolvimento do crowdsourcing em uma empresa do segmento publicitário brasileiro, nesse caso, a agência Teaser Propaganda, foi de suma importância para a construção deste estudo, pois, além de desvelar conceitos emergentes e que estão associados ao crowdsourcing, ao capital reputacional das organizações, ao desenvolvimento da web 2.0 e da sociedade em rede, é um case de sucesso promovido por uma organização empresarial estrategicamente localizada na Região Nordeste do Brasil, próxima à nossa realidade.

Ainda, refletindo sobre os achados deste estudo, observamos que a estratégia tradicional de marketing necessita ser repensada e muito bem elaborada para que seja viável para as organizações garantirem a manutenção da reputação de suas marcas em um contexto que exige cada vez mais transparência e menos disparidade de informação. Desse modo, o estabelecimento da inovação aberta nas organizações empresariais poderá atuar como fator de elevação da competitividade, funcionando como diferencial e influenciando diretamente na qualidade, expectativa e credibilidade dos produtos e serviços ofertados na ótica dos consumidores. Desenvolvendo, assim, um vínculo afetivo que resultará em uma fidelização do cliente, que compartilha boas informações sobre a marca. Isso não só poderá afetar na conquista de novos clientes, mas também, internamente, na motivação dos colaboradores, por estarem inseridos em uma comunidade de práticas bem faladas, ou seja, refletindo diretamente em sua produtividade.

O que se percebeu ao longo desse estudo, é que existe uma imensa gama de vantagens quando se adotam estratégias de marketing alinhadas aos princípios da 
organização empresarial, especialmente, quando o recurso que possuirá a missão de traduzir essa questão for o crowdsourcing, conforme foi demonstrado nos case da agência Teaser Propaganda e da plataforma 99 Designs.

A ampla concorrência entre as empresas é considerada um fator impulsionador para a formatação de novas iniciativas de negócios que passam a ser integrados em redes, vislumbrando a ampliação de seus mercados e a conquista por novos consumidores. Para tanto, esses negócios necessitarão desenvolver práticas que os diferencie no mercado, de uma maneira que seu público-alvo se identifique com eles. No caso da Teaser Propaganda, o que percebemos é que ela não apenas desenvolveu uma plataforma de crowdsourcing para criação do seu portal eletrônico, mas, além disso, elaborou campanhas que tinham o intuito de divulgar o sucesso dessa iniciativa. Essas campanhas foram desenvolvidas por meio da elaboração de vídeos didáticos que tinham a clara intenção de atrair as pessoas que porventura não estiveram presentes no processo de brainstorm, mas que se identificaram com essa iniciativa posteriormente.

Em se tratando das implicações gerenciais, ressaltamos que a empresa Teaser Propaganda utilizou o crowdsourcing como estratégia para o desenvolvimento de seu negócio por constatar que possui uma forte dependência das ideias criativas de seus colaboradores. Por este motivo, acreditamos que uma contribuição importante deste trabalho foi o de evidenciar que as organizações empresariais concebidas no capitalismo cognitivo necessitam repensar suas estratégias de atuação, especificamente, no segmento publicitário brasileiro, pois, conforme foi demonstrado, no contexto atual, os consumidores passam a interagir na esfera cultural, nas chamadas comunidades de afinidades, nas quais suas necessidades individuais emergem e em que se observam o desprendimento desses indivíduos, que passam a interagir em uma dimensão coletiva. Deste modo, as organizações devem repensar a dinamicidade de seus modelos de negócios e adequá-los a esse novo ambiente, além de observar potenciais tecnologias existentes no ambiente externo, ou seja, para além de suas fronteiras.

Finalmente, como forma de contribuição para a realização de pesquisas futuras, acreditamos que o desenvolvimento de estudos que se debruçassem por compreender a dinâmica atual do segmento publicitário brasileiro, as suas principais tecnologias de gestão e o grau de dinamicidade que a utilização do crowdsourcing poderia conceder a esse segmento, seriam importantes para o aprofundamento teórico sobre o tema bem como na constituição de um documento norteador para o avanço das empresas inseridas no segmento. Além disso, seria interessante estudar os obstáculos existentes para o desenvolvimento dos modelos de negócios baseados no crowdsourcing, especialmente, quando eles não têm o suporte necessário para se constituírem. 


\title{
The crowdsourcing as competitiveness factor in publicity: the case of Teaser Propaganda
}

\begin{abstract}
The dynamics of transformations generated by globalization and the development of Information and Communication Technologies directly affect the economic and social relations in the contemporary world. In this context, organizations need to develop new strategies for improvement of their products and services. The aim of this study is to understand the history of crowdsourcing in advertising, stressing the importance of collective participation in the advent of new technologies. We developed a qualitative case study in order to understand the main concepts related to crowdsourcing in advertising strategies. The results demonstrated how this strategy can be useful to form a network of collaborators approaching user and brand and making it the buyer client.
\end{abstract}

Keywords: Crowdsourcing. Strategy. Teaser Propaganda.

\section{El crowdsourcing como factor de competitividad en la publicidad: el caso de la Teaser Propaganda}

\section{Resumen}

La dinámica de las transformaciones generadas por la globalización y el desarrollo de las Tecnologías de la Información y la Comunicación y afectan directamente a las relaciones económicas y sociales en el mundo contemporáneo. En este contexto, las organizaciones necesitan desarrollar nuevas estrategias para la mejora de sus productos y servicios. El objetivo de este estudio es comprender la historia de crowdsourcing en la publicidad, haciendo hincapié en la importancia de la participación colectiva en el advenimiento de nuevas tecnologías. Hemos desarrollado un estudio cualitativo de casos con el fin de comprender los principales conceptos relacionados con el crowdsourcing en las estrategias de publicidad. Los resultados demostraron cómo esta estrategia puede ser útil para formar una red de colaboradores que se acercan usuario y la marca y hacer que el cliente comprador.

Palabras clave: Crowdsourcing. Estrategia. Teaser Propaganda. 


\section{Nota}

1 A utilização desse termo justifica-se, pois estamos diante de mudanças profundas e que geraram alterações no sistema econômico contemporâneo, que passou de uma economia fundamentada em capital e trabalho e centrada na produção em massa para uma economia que tem como base principal o capital intelectual e que está centrada no indivíduo e na sua capacidade de construir redes e difundir o conhecimento (SILVA, 2014).

\section{Referências}

AMARAL FILHO, Lúcio Siqueira. Apontamentos iniciais sobre a publicidade colaborativa: uma colaboração para a pesquisa. Porto Alegre: ESPM Sul, 2014. 190 p.

BARICHELL, Eugenia Maria Mariano da Rocha; OLIVEIRA, Cristiane Cleveston de. O marketing viral como estratégia publicitária nas novas ambiências midiáticas. Em Questão, Porto Alegre, v. 16, n. 1, p. 29-44, 2011.

CASTELLS, Manuel. A galáxia da internet: reflexões sobre a internet, os negócios e a sociedade. Tradução Maria Luiza X. de A. Borges. Rio de Janeiro: Jorge Zahar, 2003. 244 p.

. A sociedade em rede. 13. ed. São Paulo: Paz e Terra, 2010.

CASTRO, Darlene. Sociedade da informação, inovação e cibercultura. In: CONGRESSO LUSO-AFRO-BRASILEIRO DE CIÊNCIAS SOCIAIS, 11. Salvador, 2011. Disponível em: <http://docplayer.com.br/5202908-Sociedade-da-informacao-inovacao-e-cibercultura.html>. Acesso em: 22 fev. 2016

CHESBROUGH, Henry. The logic of open innovation: managing intellectual property. California Management Review, Berkeley, v. 45, n. 3, p. 33-58, 2003.

COCCO, Giuseppe; GALVÃO, Alexander Patez; SILVA, Gerardo (Org.). Capitalismo Cognitivo. Rio de Janeiro: DP\&A, 2003.

CRESWELL, J. W. Projeto de Pesquisa: métodos qualitativo, quantitativo e misto. 3. ed. Porto Alegre: Artmed/Bookman, 2010.

DENZIN, N. K. The research act: a theoretical introduction to sociological methods. New Brunswick: Transaction, 2009.

FELINTO, Erick. Videotrash: o YouTube e a cultura do "spoof" na internet. Revista Galáxia, São Paulo, n. 16, p. 33-42, dez. 2008

FREEMAN, Christopher; SOETE, Luc. The economics of industrial innovation. London: Psychology Press, 1997.

GANG GAÚCHA. Sobre a Gang. Porto Alegre: Gang Gaúcha, 2015. Disponível em: <http://gang. com.br/sobre-a-gang/>. Acesso em: 11 jul. 2015.

GARCIA, I. Uma visão antropológica das redes sociais. Harvard Business Review, v. 23, p. 5-12, 2012. Disponível em: <http://www.hbrbr.com.br/materia/uma-visao-antropologica-das-redes-sociais>. Acesso em: 11 jun. 2015.

GASKELL, G.; BAUER, M. W. Para uma prestação de contas pública: além da amostra, da fidedignidade e da validade. In: BAUER, M. W.; GASKELL, G. Pesquisa qualitativa com texto, imagem e som: um manual prático. Petrópolis: Vozes, 2002. 
HALL, Peter. Innovation, Economics and Evolution: theoretical perspectives on changing technology in economics systems. London: Harvester Wheatsheaf Publishers, 1994.

HOWE, Jeffery W. $O$ poder das multidões: por que a força da coletividade está remodelando o futuro dos negócios. Rio de Janeiro: Elsevier, 2009.

. The rise of crowdsourcing. Wired magazine, v. 14, n. 6, p. 1-4, 2006.

JENKINS, Henry. Confronting the challenges of participatory culture: Media education for the 21st century. Cambridge, MA: Mit Press, 2009.

JOHNSON, S. Swarming next time. Feed [interactive], 2001. Disponível em: <http://web.archive. org/web/20010711061231/http://www.feedmag.com/templates/default.php3?a_id=1568>. Acesso em: 15 jun. 2015.

JULIEN, P-A. Empreendedorismo regional e economia do conhecimento. São Paulo: Saraiva, 2010.

KOTLER, Philip; ARMSTRONG, Gary. Principles of Marketing. 7. ed. London: Pearson Education, 1996. $122 \mathrm{p}$.

LIMA, Telma C.S.; MIOTO, Regina Célia Tamaso. Procedimentos metodológicos na construção do conhecimento científico: a pesquisa bibliográfica. Revista Katálysis, Florianópolis, v. 10, n. 1, p. 37-45, 2007.

MACHADO FILHO, Cláudio Pinheiro. Responsabilidade social e governança: o debate e as implicações. São Paulo: Cengage Learning, 2006.

MARTINS, Gilberto de Andrade; THEÓPHILO, Carlos Renato. Metodologia da investigação científica para ciências sociais aplicadas. São Paulo: Atlas, 2007.

MUNHOZ, A. C. C. et al. Coworking e Crowdsourcing: como modelos de negócios inovadores influenciam no desenvolvimento de start-ups. In: SEMINÁRIO EM ADMINISTRAÇÃO, 16. Resumos... São Paulo: EAD-FEAUSP, 2013. Disponível em: <http://sistema.semead.com.br/16semead/ resultado/an_resumo.asp?cod_trabalho=1079>. Acesso em: 14 fev. 2016.

NASCIMENTO, Ademir Macedo et al. Teaser Propaganda: uma história de cocriação e engajamento. Revista Brasileira de Casos de Ensino em Administração, São Paulo, v. 2.179, p. 1-6, 2014. Disponível em: <https://www.researchgate.net/profile/Ademir_Nascimento/publication/265510710_Teaser_Propaganda_uma_historia_de_cocriacao_e_engajamento_Caso_de_Ensino/links/5410e7bc0cf2f2b29a4118f1.pdf>. Acesso em: 15 fev. 2016.

NASCIMENTO, Ademir Macedo; HEBER, Florence; LUFT, Maria Conceição. O uso do crowdsourcing como ferramenta de inovação aberta: uma categorização à luz da teoria de redes interorganizacionais. Revista Gestão Organizacional, v. 6, n. 2, 2014.

O'REILLY, Tim. What Is Web 2.0: design patterns and business models for the next generation of software \{OL\}. Boston: O'Reilly Media, 2005. Disponível em: <http://www.oreilly.com/pub/a/ web2/archive/what-is-web-20.html>. Acesso em: 13 fev. 2016.

PINTO, Jefferson; ANHOLON, Rosley. A inovação nas empresas e a necessidade de novos paradigmas em indicadores de desempenho. São Paulo: VII SEMEAD, 2006. Disponível em: <http://www. ead.fea.usp.br/Semead/7semead/paginas/artigos\%20recebidos/PGT/PGT01-_A_inova\%E7\%E3o_ nas_empresas.PDF $>$. Acesso em: 11 jun. 2015.

RICHARDSON, Roberto J. Pesquisa social: métodos e técnicas. São Paulo: Atlas, 1999. 334 p.

Teoria e Evidência Econômica - Ano 22, n. 47, p. 413-432, jul./dez. 2016 
SILVA, A. D. F. O processo regulador na [re]conversão de um Arranjo Produtivo Local: o caso do Portomídia - Centro de Empreendedorismo e Tecnologia da Economia Criativa. Dissertação (Mestrado em Administração) - Universidade Federal de Pernambuco, Recife, 2014.

SILVA, Guilherme. O crowdsourcing no design publicitário: análise do site 99 Designs. Trabalho de Conclusão de Curso (Graduação em Publicidade e Propaganda) - Universidade Federal do Rio Grande do Sul, Porto Alegre, 2001. Disponível em: <https://www.lume.ufrgs.br/bitstream/ handle/10183/37575/000820272.pdf?sequence=1>. Acesso em: 11 jun. 2015.

STAKE. R. The art of case study research. 2. ed. London: Sage, 1999.

SUROWIECKI, J. A Sabedoria das Multidões. Rio de Janeiro: Record, 2006.

TADEL, François et al. Brainstorm: a user-friendly application for MEG/EEG analysis. Computational intelligence and neuroscience, New Yorc, v. 2011, n. 8, p. 1-13, 2011.

TEASER PROPAGANDA. Site corporativo. 2012. Disponível em: <http://teaserpropaganda.com/ agencia>. Acesso em: 11 jul. 2015

. Teaser Propaganda: case site cocriativo. Vídeocase. 2011. Disponível em: <https://www. youtube.com/watch?v=qEXqlXk45fA $>$. Acesso em: 13 jun. 2015.

VICKERY, Graham; WUNSCH-VINCENT, Sacha. Participative web and user-created content: Web 2.0 wikis and social networking. Paris: Organization for Economic Cooperation and Development (OECD), 2007.

WERSIG, Gernot. Information science: the study of postmodern knowledge usage. Information processing \& management, London, v. 29, n. 2, p. 229-239, 1993.

ZATTI, R.; FERRARI, A.; BELALIAN, D. Ideias.me. Disponível em: <http://crowdoque.typepad. com>. Acesso em: 8 jun. 2015. 